\title{
Oral fluoropyrimidine S-1 combined with leucovorin is a promising therapy for colorectal cancer: Evidence from a xenograft model of folate-depleted mice
}

\author{
SAYAKA TSUKIOKA, JUNJI UCHIDA, HIROAKI TSUJIMOTO, FUMIO NAKAGAWA, \\ YOSHIKAZU SUGIMOTO, TOSHINORI OKA and MAMORU KINIWA
}

Tokushima Research Center, Taiho Pharmaceutical Co., Ltd., Kawauchi-cho, Tokushima 771-0194, Japan

Received November 14, 2008; Accepted January 21, 2009

DOI: $10.3892 / \mathrm{mmr} 00000111$

\begin{abstract}
The oral fluoropyrimidine S-1 has marked efficacy in treating metastatic colorectal cancer patients. In the present study, we explored the therapeutic potential of combined in vivo treatment in the human colon cancer cell lines COL-1, KM12C and KM20C with consecutive oral S-1 and leucovorin $(\mathrm{LV})$ in 2-week therapeutic periods. This combination had increased anticancer activity compared to S-1 alone in the xenografts tested. Moreover, oral S-1/LV treatment showed a more potent anticancer effect on COL-1 xenografts than infusional 5-fluorouracil (5-FU)/LV, with comparable loss of body weight. The reduced folate level in the tumors was initially low, but rapidly rose and persisted for a long period of over $24 \mathrm{~h}$ after a single LV administration. This resulted in the formation of much higher levels of the ternary complex with thymidylate synthase (TS) and 5-fluoro-2'-deoxyuridine 5'-monophosphate (FdUMP) derived from 5-FU, leading to a prolonged inhibition of TS activity in combined administration with oral S-1. These results suggest that the co-administration of LV with S-1 might improve therapeutic efficacy in the treatment of colorectal cancer patients.
\end{abstract}

\section{Introduction}

Colorectal cancer (CRC) is one of the most common causes of malignancy-related deaths in the world. Although 5-fluorouracil (5-FU) combined with leucovorin (LV) has played a key role in the treatment of patients with CRC, it has disadvantages, such as the long-term venous access needed for alternative modalities. In Japan, several oral fluoropyrimidines, such as tegafur/uracil (UFT), have been used with or without oral LV to improve the prognosis and quality of life for patients with CRC in both advanced and

Correspondence to: Dr Mamoru Kiniwa, Tokushima Research Center, Taiho Pharmaceutical Co., Ltd., 224-2 Hiraishi-ebisuno, Kawauchi-cho, Tokushima 771-0194, Japan

E-mail: makiniwa@taiho.co.jp

Key words: 5-fluorouracil, leucovorin, reduced folate, S-1, thymidylate synthase adjuvant settings (1-3). S-1 is an orally active combined formulation of tegafur (FT; a prodrug of 5-FU that is converted to 5-FU mainly in the liver), gimeracil (CDHP; an inhibitor of dihydropyrimidine dehydrogenase that degrades 5-FU), and oteracil (Oxo; an inhibitor of the phosphorylation of 5-FU in the gastrointestinal tract, which thereby reduces the toxic gastrointestinal effects of the drug) at molar ratios of 1:0.4:1 $(4,5)$. The efficacy of S-1 for the treatment of advanced or metastatic gastric cancer and CRC has been demonstrated in clinical studies $(6,7)$; however, limited information is currently available with regard to S-1/LV combination therapy for CRC.

One of the major mechanisms of action of S-1 and 5-FU is the inhibition of thymidylate synthase (TS). TS forms a covalent ternary complex with an active metabolite of 5-FU, 5-fluoro-2'-deoxyuridine 5'-monophosphate (FdUMP), in the presence of the folate co-factor, 5,10-methylenetetrahydrofolate $\left(\mathrm{CH}_{2} \mathrm{FH}_{4}\right)(8)$. LV increases the intracellular level of $\mathrm{CH}_{2} \mathrm{FH}_{4}$ in vitro $(9,10)$ and in vivo $(11,12)$, and potentiates the cytotoxicity of fluoropyrimidines $(13,14)$ and their anticancer activity (15-18). It should be noted, however, that the effect of LV on the efficacy of 5-FU is masked in conventional mouse xenograft models, since the folate pool is higher in mice fed a normal diet than it is in humans $(19,20)$.

The current study used mice with low folate levels in their blood and tumor tissues, termed 'folate-depleted mice', to assess the impact of the co-administration of $\mathrm{LV}$ on the anticancer effect of S-1 and infusional 5-FU. The folatedepleted mice were obtained by feeding the animals a lowfolate diet. In addition, we investigated the intratumoral level of reduced folate and TS activity after treatment with the drugs, in order to assess the effect of LV co-administration on TS inhibition by $\mathrm{S}-1$.

\section{Materials and methods}

Materials. FT, CDHP, Oxo and LV were produced by Taiho Pharmaceutical Co., Ltd. (Tokyo, Japan). An injectable formulation of 5-FU was purchased from Kyowa Hakko Kogyo Co., Ltd. (Tokyo, Japan). Hydroxypropylmethylcellulose (HPMC) was purchased from Shin-Etsu Chemical Co., Ltd. (Tokyo, Japan), and $\left[6-{ }^{3} \mathrm{H}\right]$ FdUMP from Moravek Biochemicals Inc. (Brea, CA). All other chemicals used were commercially available. 
Animals. Male BALB/cA-nu/nu mice (4-5 weeks of age) were purchased from Clea Japan Inc. (Tokyo, Japan) and were fed a low-folate pellet diet (AIN-93M-based Folate-Deficient Rodent Diet; Oriental Yeast Co., Ltd., Tokyo, Japan) with ad libitum access to filtered water. Note that the low-folate diet contained $10 \%$ of the folate of the normal diet. The mice were kept in laminar air-flow units for the duration of the experiments, all of which were performed in compliance with the regulations of the Animal Experimentation Committee of Taiho Pharmaceutical Co., Ltd.

Cell lines. The human CRC cell line COL-1 was obtained from the Central Institute for Experimental Animals, Kawasaki, Japan. KM12C and KC20C were kindly provided by Dr Morikawa of the National Cancer Institute, Tokyo, Japan.

Drug preparation and administration. S-1 was prepared by mixing FT, CDHP and Oxo at molar ratios of 1:0.4:1 in $0.5 \%$ HPMC solution. The doses of S-1 were expressed as the doses of FT contained within them. LV was suspended in $0.5 \%$ HPMC solution. S-1 (6.9 or $8.3 \mathrm{mg} / \mathrm{kg} /$ day) and LV (10 or $20 \mathrm{mg} / \mathrm{kg} /$ day) were orally administered from day 1 to day 9 or day 14. 5-FU was prepared by dilution with sterile saline solution and was continuously infused at $15 \mathrm{mg} / \mathrm{kg} / \mathrm{day}$ ( $0.012 \mathrm{ml} /$ day). Continuous infusion was performed by subcutaneous implantation of an Alzet osmotic pump (type 2002; Durect Co., Cupertino, CA, USA) filled with 5-FU solution.

Antitumor experiments. Human tumor xenografts were prepared by subcutaneous implantation of a tumor fragment $(\sim 2 \mathrm{~mm}$ in diameter) into the right-hand side of the back of each nude mouse (at $\sim 5$ weeks of age). Approximately 2 weeks after tumor implantation, the animals were allocated to control and treatment groups in such a way as to make the average tumor volume (TV) the same in both groups. The drugs were administered to the mice for 9 or 14 consecutive days in order to evaluate their antitumor effects. Tumor size and body weight were measured twice weekly throughout the experimental period. TV, the tumor growth inhibition (TGI) rate and body weight change (BWC) were calculated as follows:

TV $\left(\mathrm{mm}^{3}\right)=$ length $(\mathrm{mm}) \mathrm{x}$ width $(\mathrm{mm}) \mathrm{x}$ width $(\mathrm{mm}) \times 0.5$

TGI $(\%)=[1-$ mean TV of treatment group/mean TV of control group] x 100

BWC $(\%)=[($ mean body weight at day 10 or $15 /$ mean body weight at day 0) - 1] x 100

Determination of intratumoral reduced folate level. Animals were sacrificed at the indicated times. The tumors were rapidly frozen in liquid nitrogen and stored at $-80^{\circ} \mathrm{C}$. The assay for reduced folate is based on the entrapment of $\mathrm{CH}_{2} \mathrm{FH}_{4}$ into a stable ternary complex with excess recombinant human TS protein and excess $\left[6-{ }^{3} \mathrm{H}\right] \mathrm{FdUMP}$ (19). Since $\mathrm{CH}_{2} \mathrm{FH}_{4}$ can potentially be dissociated into $\mathrm{FH}_{4}$ and formaldehyde under these conditions, the sum of these folates is measured. Tumor tissues were homogenized with 3 volumes of ice-cold $10 \mathrm{mM}$ phosphate buffer ( $\mathrm{pH} 7.0$ ) containing $2 \mathrm{mg} / \mathrm{ml}$ ascorbic acid and $40 \mathrm{mM} 2$-mercaptoethanol. After centrifugation at $105,000 \mathrm{~g}$, the supernatants were collected. An aliquot of the supernatant was used to determine the soluble protein by the Bradford method. The remainder of the supernatant was diluted with homogenizing buffer to $4 \mathrm{mg}$ protein $/ \mathrm{ml}$, then placed immediately in a boiling water bath for $1 \mathrm{~min}$ and centrifuged to remove the precipitated protein. The supernatant was used for folate determination in a reaction mixture containing $5 \mu \mathrm{g}$ recombinant human TS protein, $125 \mathrm{nM}$ [6- $\left.{ }^{3} \mathrm{H}\right]$ FdUMP $(555 \mathrm{GBq} / \mathrm{mmol})$ and $6.5 \mathrm{mM}$ formaldehyde in $200 \mu \mathrm{l}$ of $50 \mathrm{mM}$ Tris- $\mathrm{HCl}$ buffer (pH 7.4). The supernatant (50 $\mu \mathrm{l}$ ) was added to $200 \mu \mathrm{l}$ of the reaction mixture and incubated at $30^{\circ} \mathrm{C}$ for $50 \mathrm{~min}$, and then the radioactivity in the acid-insoluble fraction was measured with a liquid scintillation counter (Tri-Carb 2000CA; Packard Instruments, Meriden, CT, USA).

Determination of thymidylate activity. TS activity was determined as the number of $\left[6-{ }^{3} \mathrm{H}\right] \mathrm{FdUMP}$ binding sites in the $105,000 \mathrm{~g}$ supernatant of tumor tissue homogenates as described by Spears and Gustavsson (21). The supernatant was incubated with $\left[6-{ }^{3} \mathrm{H}\right] \mathrm{FdUMP}$ in the presence of excess $\mathrm{CH}_{2} \mathrm{FH}_{4}$ for $20 \mathrm{~min}$ at $30^{\circ} \mathrm{C}$, and the radioactivity in the acidinsoluble fraction was measured with a liquid scintillation counter.

Western blotting. Samples of lysates containing $40 \mu \mathrm{g}$ protein were resolved by sodium dodecyl sulfate polyacrylamide gel electrophoresis (SDS-PAGE), transferred to polyvinylidene fluoride (PVDF) membranes, blocked in blocking solution (UK-B80; DS Pharma Biomedical Co., Ltd., Osaka, Japan) and incubated with primary antibodies (anti-human TS antibody diluted at 1:5000; Taiho Pharmaceutical, Saitama, Japan and anti-human B-actin antibody diluted at 1:10000, \#A5441; Sigma, St. Louis, MO, USA) for $1 \mathrm{~h}$ at room temperature. Membranes were washed three times for $10 \mathrm{~min}$ each in TBST (20 mM Tris-HCl, pH 7.5, $150 \mathrm{mM} \mathrm{NaCl}, 0.05 \%$ Tween-20) and incubated with horseradish peroxidaseconjugated secondary antibodies for $1 \mathrm{~h}$ at room temperature. After three 10-min washes, the membranes were incubated with enhanced ECL reagent (\#34096 Thermo; Rockford, IL, USA) for $1 \mathrm{~min}$, and the chemiluminescence was detected with LAS 3000 (Fujifilm, Tokyo, Japan).

Statistical analysis. The significance of differences in TV was analyzed with the Student's t-test using EXSAS (version 7.11; Arm Co., Ltd., Osaka, Japan). p<0.05 was considered to be statistically significant.

\section{Results}

Human tumor xenografts in nude mice fed a low-folate diet. We initially established an in vivo xenograft model in which LV treatment elevated the intratumoral folate pool. The concentrations of reduced folate in COL-1, KM12C and KM20C tissues removed from xenografted mice fed a normal diet were $44.2 \pm 10.7,23.4 \pm 7.8$ and $13.0 \pm 6.2 \mathrm{pmol} / \mathrm{mg}$ protein, respectively; these levels were unchanged by LV treatment (data not shown). In contrast, as illustrated in Fig. 1, the basal levels of reduced folate in COL-1, KM12C and KM20C tissues 


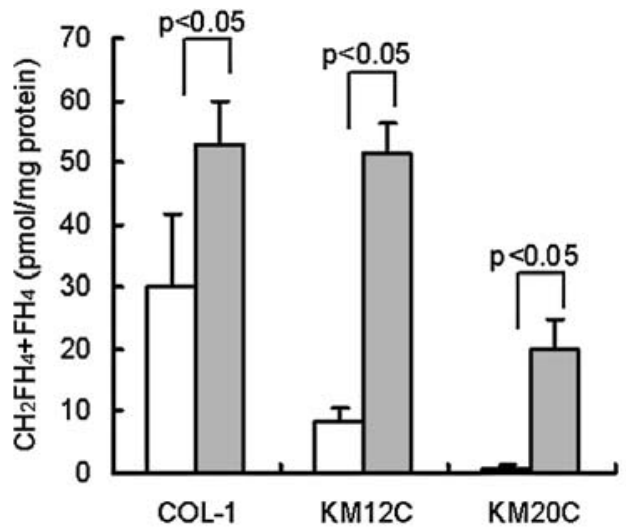

Figure 1. Intratumoral reduced folate levels in mice fed a low-folate diet. Folate-depleted mice bearing human colorectal cancer tumors were administered oral vehicle alone (open columns) or a single dose of $10 \mathrm{mg} / \mathrm{kg} / \mathrm{day}$ leucovorin (shaded columns). After $24 \mathrm{~h}$, tumor tissues were isolated and reduced folate was measured. Values are the mean \pm standard deviation (SD) of three mice.

from xenografted mice fed a low-folate diet for 1 week were $30.0 \pm 11.7,8.3 \pm 2.3$ and $0.8 \pm 0.7 \mathrm{pmol} / \mathrm{mg}$ protein, respectively. A single $10 \mathrm{mg} / \mathrm{kg}$ oral dose of LV significantly increased the reduced folate levels in the tumors from folate-depleted mice (Fig. 1).

Anticancer activity of $S-1$ combined with leucovorin. Using folate-depleted mice, we investigated whether LV treatment affected the anticancer activity of S-1. Treatment with S-1 alone at a dose of $8.3 \mathrm{mg} / \mathrm{kg} /$ day reduced tumor growth without affecting the BWC (Fig. 2). The anticancer activity of $\mathrm{S}-1$ was enhanced by the co-administration of $10 \mathrm{mg} / \mathrm{kg} /$ day of $\mathrm{LV}$, whereas the administration of LV alone had no influence on tumor growth or the BWC (data not shown). The coadministration of LV and S-1 resulted in a decrease in body weight, although this effect was tolerable. These results show that LV treatment can enhance the anticancer activity of S-1.

We next compared the effect of LV on the anticancer activities of S-1 and infusional 5-FU. In this experiment, nude mice bearing COL-1 cells were treated with $5-\mathrm{FU} / \mathrm{LV}$ and
Table I. Comparison of anticancer effect of S-1/leucovorin and infusional 5-fluorouracil/leucovorin.

\begin{tabular}{lcccc}
\hline Treatment & $\begin{array}{c}\text { TV }\left(\mathrm{mm}^{3}\right) \\
(\text { mean } \pm \text { SD) }\end{array}$ & TGI $(\%)$ & $\begin{array}{c}\text { BWC (g) } \\
(\text { mean } \pm \text { SD) }\end{array}$ & \\
\hline Control & $1370 \pm 109$ & - & $-3.86 \pm 1.47$ & \\
S-1 & $546 \pm 62^{\mathrm{a}, \mathrm{b}}$ & 60.6 & $-3.59 \pm 1.47$ & NS \\
S-1/LV & $396 \pm 24^{\mathrm{a}, \mathrm{b}}$ & 71.1 & $-5.27 \pm 1.45$ & NS \\
5-FU & $704 \pm 66^{\mathrm{a}}$ & 48.4 & $-4.12 \pm 1.86$ & \\
5-FU/LV & $476 \pm 35^{\mathrm{a}}$ & 65.3 & $-5.89 \pm 1.36$ & \\
\hline
\end{tabular}

Mice fed a low-folate diet were implanted with COL-1 tumor fragment. S-1 $(6.9 \mathrm{mg} / \mathrm{kg} /$ day $)$ and leucovorin (LV) $(20 \mathrm{mg} / \mathrm{kg} /$ day) were orally administrated for 14 consecutive days, whereas 5-fluorouracil (5-FU) $(15 \mathrm{mg} / \mathrm{kg} /$ day $)$ was continuously infused for 14 days by s.c. implantation of an Alzet osmotic pump. At day 15, tumor volume (TV) and body weight change (BWC) were evaluated. Values indicate the mean of 7 mice \pm SD. Statistical analysis was performed using the Student's t-test. ${ }^{\mathrm{a}} \mathrm{p}<0.05$ vs. control group, ${ }^{\mathrm{b}} \mathrm{p}<0.05$ vs. 5 -FU or 5 -FU/LV group, NS, not significant vs. the 5-FU or 5-FU/LV group. TGI, tumor growth inhibition.

$\mathrm{S}-1 / \mathrm{LV}$ at the maximal tolerable doses. As shown in Table I, $\mathrm{S}-1$ treatment at $6.9 \mathrm{mg} / \mathrm{kg} /$ day and $5-\mathrm{FU}$ treatment at $15 \mathrm{mg} /$ $\mathrm{kg}$ /day reduced tumor growth $(\mathrm{p}<0.05)$, and $\mathrm{S}-1$ alone was more potent than the infusional 5-FU $(\mathrm{p}<0.05)$. However, S-1/LV clearly inhibited tumor growth more effectively than $5-\mathrm{FU} / \mathrm{LV}(\mathrm{p}<0.05)$. The BWC values, by contrast, were not significantly different.

Effects of leucovorin on reduced folate levels and tumor thymidylate synthase activity. We measured intratumoral reduced folate levels after $\mathrm{LV}$ treatment at $10 \mathrm{mg} / \mathrm{kg}$ and compared intratumoral TS activities following the administration of S-1 $(8.3 \mathrm{mg} / \mathrm{kg})$ alone and S-1 combined with $\mathrm{LV}$ at $10 \mathrm{mg} / \mathrm{kg}$. The reduced folate levels in the COL-1 xenografts rose rapidly and remained at a high level for $24 \mathrm{~h}$ (Fig. 3A). TS activity in the tumor tissues was strongly inhibited after treatment with S-1 alone, and the maximum inhibition was
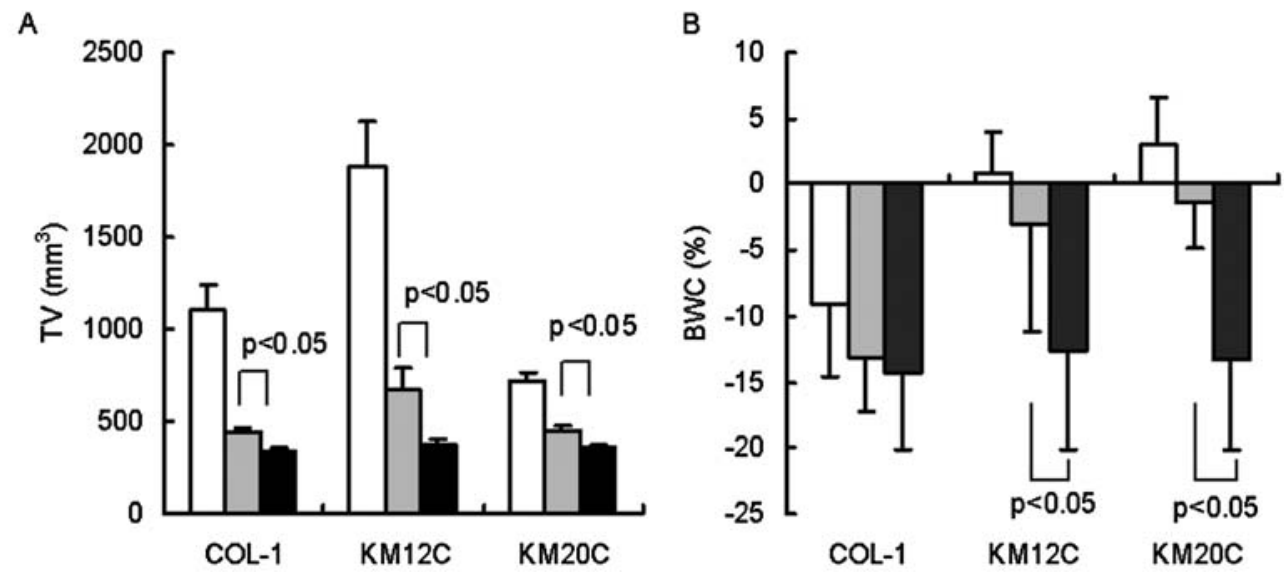

Figure 2. Anticancer activity and body weight change (BWC) following S-1 plus leucovorin treatment. Folate-depleted mice bearing human colorectal cancer tumors were administered oral vehicle (open columns), S-1 alone (gray columns) or S-1/LV (black columns) for 9 consecutive days. Panels A and B respectively show tumor volume (TV) and BWC on day 10 . Values are the mean \pm SD of 10 mice. $p<0.05$ was considered to be statistically significant. 
A

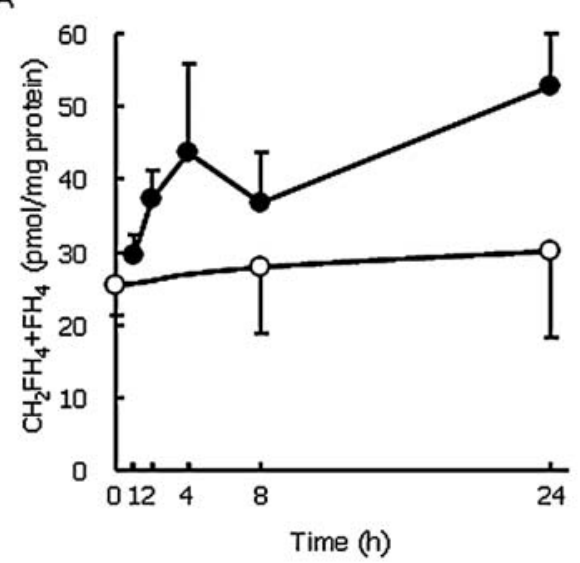

B

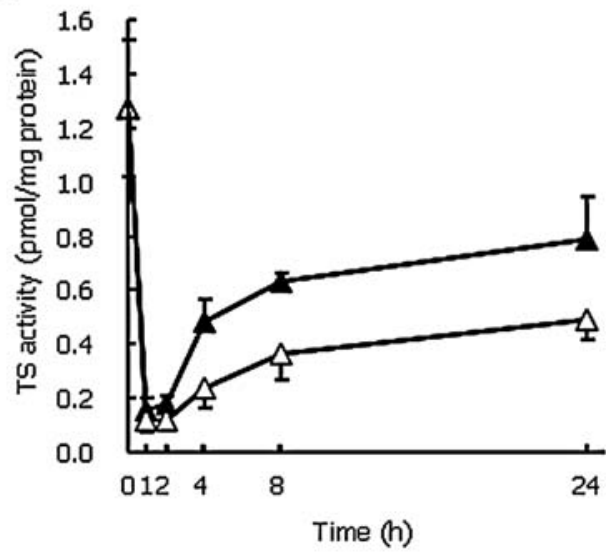

Figure 3. Changes in the intratumoral level of reduced folate and thymidylate synthase (TS) inhibition by leucovorin (LV). Folate-depleted mice bearing COL-1 tumors were used for these experiments. (A) Intratumoral reduced folate levels after LV administration were determined at the indicated times after a single administration of vehicle alone (open circles) or LV at $10 \mathrm{mg} / \mathrm{kg}$ (closed circles). (B) TS activity in tumor tissues was measured after oral administration of S-1 at $8.3 \mathrm{mg} / \mathrm{kg}$ (open triangles) alone or in combination with $\mathrm{LV}$ at $10 \mathrm{mg} / \mathrm{kg}$ (closed triangles). Values are the mean $\pm \mathrm{SD}$ of six mice.
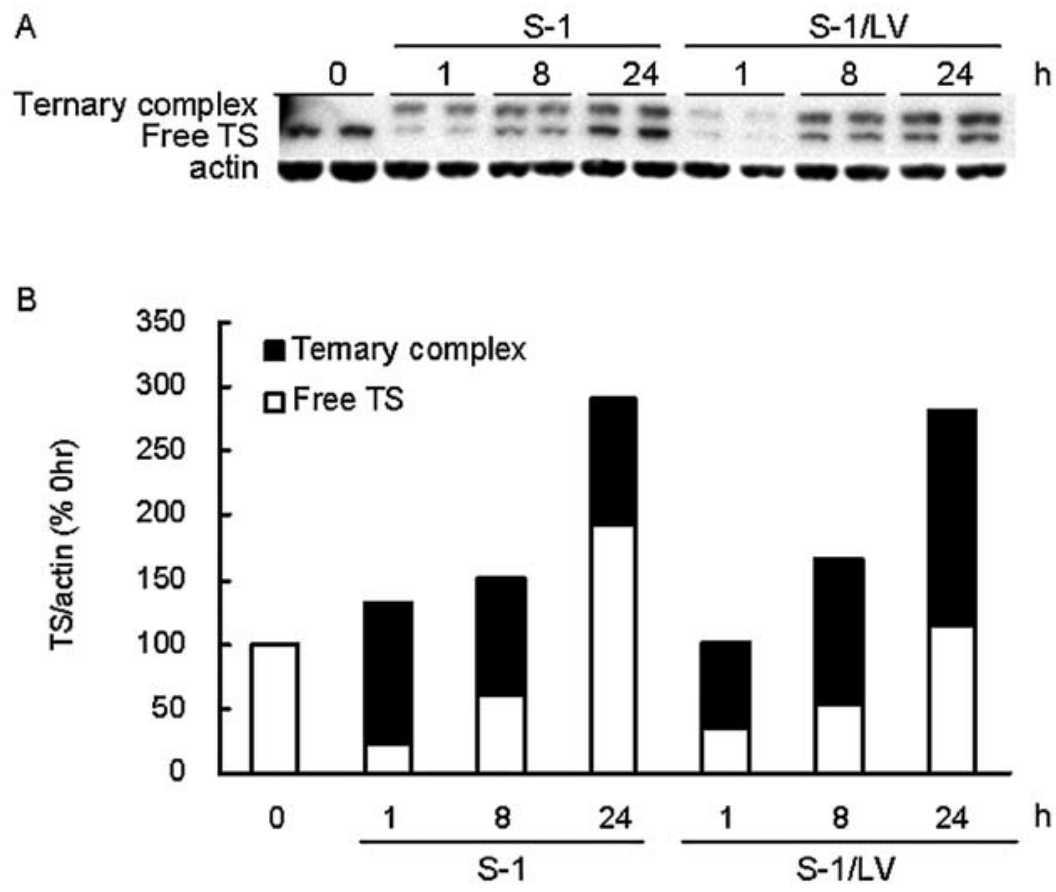

Figure 4. Measurement of ternary complexes after S-1 or S-1/leucovorin (LV) treatment. Folate-depleted mice bearing COL-1 tumors were used for this experiment. (A) Free TS protein and ternary complexes were detected by Western blotting at indicated times after a single administration of S-1 (8.3 mg/kg) alone or in combination with LV (10 mg/kg). Levels of actin are shown as loading controls. (B) The band intensities of free TS (open columns) and ternary complexes (closed columns) were measured and calibrated with actin. The value of free TS at $0 \mathrm{~h}$ was set as $100 \%$.

observed at $1 \mathrm{~h}$. The TS activity then partially recovered at $4 \mathrm{~h}$ but remained suppressed at $24 \mathrm{~h}$. Evidently, the coadministration of LV prolongs the inhibition of TS activity in tumor tissues (Fig. 3B).

Effect of LV on the stability of the ternary complex. We measured the free TS protein and ternary complexes using Western blotting after treatment with S-1 (8.3 mg/kg) alone or $\mathrm{S}-1$ combined with $\mathrm{LV}$ at $10 \mathrm{mg} / \mathrm{kg}$ in nude mice bearing COL-1 tumors (Fig. 4). The free TS protein level fell immediately as a result of ternary complex formation. At $24 \mathrm{~h}$ after drug treatment, the free TS level had recovered and the total
TS level had increased. Treatment with S-1 alone or S-1/LV increased the total TS protein level equally. However, we observed a much higher level of ternary complex formation and a much greater reduction in free TS after treatment with S-1/LV, compared to treatment with S-1 alone.

\section{Discussion}

Fluoropyrimidine derivatives have been shown to exert anticancer effects primarily through the inhibition of TS by forming covalent ternary complexes with FdUMP and a representative reduced folate, $\mathrm{CH}_{2} \mathrm{FH}_{4}$. An adequate level of 
reduced folate is, therefore, required for the anticancer activity of these agents. For instance, Spears et al reported that inadequate $\mathrm{CH}_{2} \mathrm{FH}_{4}$ levels were responsible for half of the patients who showed poor TS inhibition after 5-FU treatments (22). In the present study, we used folate-depleted mice to evaluate the anticancer activity of $\mathrm{S}-1 / \mathrm{LV}$ on human colon cancer xenografts. The basal level of intratumoral reduced folate was significantly lower in these mice than in mice fed a normal diet. These results are in agreement with those of Schmitz et al (20), who reported that folate levels in the blood of folate-depleted mice were similar to those in humans. More important was the observation that the intratumoral reduced folate level was elevated by $\mathrm{LV}$ treatment in tumors of all three lines, regardless of basal level. Our findings indicate that the folate-depleted xenograft model used in the present study is useful for investigating the role of reduced folate in the anticancer activities of fluoropyrimidine derivatives, such as $\mathrm{S}$-1. In fact, experiments using folate-depleted mice have demonstrated that LV treatment significantly enhances the anticancer effect of S-1. Of note, oral S-1/LV therapy inhibited the growth of COL-1 tumors more effectively than the infusion of 5-FU/LV when administered at doses of similar toxicity. As previously reported (5), this result may be explained by the protective effect of Oxo, a component of S-1, against 5-FUinduced gastrointestinal toxicity.

To further analyze the effect of LV on the anticancer activity of S-1, we carried out time-course experiments. The intratumoral reduced folate level was rapidly elevated after LV treatment and was maintained for $24 \mathrm{~h}$. Changes in the levels of reduced folate seemed to parallel changes in TS activity in the tumor tissue; TS activity was strongly inhibited by both $\mathrm{S}-1$ alone and $\mathrm{S}-1 / \mathrm{LV}$ at 1 or $2 \mathrm{~h}$, and then partially recovered at $4 \mathrm{~h}$ and thereafter. These results are in reasonable agreement with the finding that FT, contained in S-1, is rapidly degraded in mice (23). Of note, we found that the co-administration of LV continued to enhance TS inhibition at $24 \mathrm{~h}$ after treatment. This finding is supported by the observation that a much greater amount of ternary complex was formed at $24 \mathrm{~h}$ after the single administration of $\mathrm{S}-1 / \mathrm{LV}$ than after the administration of S-1 alone, and can be explained by the increased levels of intratumoral reduced folate, which possibly stabilized the ternary complex $(14,24-27)$. On the other hand, the accumulation of ternary complex in tumor cells after fluoropyrimidine treatment is reportedly capable of inducing TS translation (28). However, a much lower amount of free TS was detected in tumor tissue treated with $\mathrm{S}-1 / \mathrm{LV}$ than in tumor tissue treated with S-1 alone. Moreover, the resultant free TS protein after S-1/LV treatment seemed to be partially inactive. We are currently investigating the mechanism by which S-1/LV treatment interferes with TS translation.

Collectively, the administration of oral LV significantly enhanced the anticancer activity of S-1, and was accompanied by an acceptable decrease in body weight. We therefore propose that the clinical efficacy of combination therapy with oral S-1/LV warrants evaluation as a treatment for CRC.

\section{Acknowledgements}

We are grateful to Dr Masakazu Fukushima for the helpful advice.

\section{References}

1. Douillard JY, Hoff PM, Skillings JR, Eisenberg P, Davidson N, Harper P, Vincent MD, Lembersky BC, Thompson S, Maniero A and Benner SE: Multicenter phase III study of uracil/tegafur and oral leucovorin versus fluorouracil and leucovorin in patients with previously untreated metastatic colorectal cancer. J Clin Oncol 20: 3605-3616, 2002.

2. Carmichael J, Popiela T, Radstone D, Falk S, Borner M, Oza A, Skovsgaard T, Munier S and Martin C: Randomized comparative study of tegafur/uracil and oral leucovorin versus parenteral fluorouracil and leucovorin in patients with previously untreated metastatic colorectal cancer. J Clin Oncol 20: 3617-3627, 2002.

3. Lembersky BC, Wieand HS, Petrelli NJ, O'Connell MJ, Colangelo LH, Smith RE, Seay TE, Giguere JK, Marshall ME, Jacobs AD, Colman LK, Soran A, Yothers G and Wolmark N: Oral uracil and tegafur plus leucovorin compared with intravenous fluorouracil and leucovorin in stage II and III carcinoma of the colon: results from National Surgical Adjuvant Breast and Bowel Project Protocol C-06. J Clin Oncol 24: 2059-2064, 2006.

4. Diasio RB: Clinical implications of dihydropyrimidine dehydrogenase inhibition. Oncology 13: 17-21, 1999.

5. Shirasaka T, Shimamato Y, Ohshimo H, Yamaguchi M, Kato T, Yonekura K and Fukushima M: Development of a novel form of an oral 5-fluorouracil derivative (S-1) directed to the potentiation of the tumor selective cytotoxicity of 5-fluorouracil by two biochemical modulators. Anticancer Drugs 7: 548-557, 1996.

6. Koizumi W, Narahara H, Hara T, Takagane A, Akiya T, Takagi M, Miyashita K, Nishizaki T, Kobayashi O, Takiyama W, Toh Y, Nagaie T, Takagi S, Yamamura Y, Yanaoka K, Orita H and Takeuchi M: S-1 plus cisplatin versus S-1 alone for first-line treatment of advanced gastric cancer (SPIRITS trial): a phase III trial. Lancet Oncol 9: 215-221, 2008.

7. Ohtsu A, Baba H, Sakata Y, Mitachi Y, Horikoshi N, Sugimachi K and Taguchi T: Phase II study of S-1, a novel oral fluorophyrimidine derivative, in patients with metastatic colorectal carcinoma. S-1 Cooperative Colorectal Carcinoma Study Group. Br J Cancer 83: 141-145, 2000.

8. Danenberg PV, Langenbach RJ and Heidelberger C: Structures of reversible and irreversible complexes of thymidylate synthetase and fluorinated pyrimidine nucleotides. Biochemistry 13: 926-933, 1974.

9. Matherly LH, Czajkowski CA, Muench SP and Psiakis JT: Role for cytosolic folate-binding proteins in the compartmentation of endogenous tetrahydrofolates and the 5-formyl tetrahydrofolatemediated enhancement of 5-fluoro-2'-deoxyuridine antitumor activity in vitro. Cancer Res 50: 3262-3269, 1990.

10. Park JG, Collins JM, Gazdar AF, Allegra CJ, Steinberg SM, Greene RF and Kramer BS: Enhancement of fluorinated pyrimidine-induced cytotoxicity by leucovorin in human colorectal carcinoma cell lines. J Natl Cancer Inst 80: 1560-1564, 1988.

11. Nadal JC, van Groeningen CJ, Pinedo HM and Peters GJ: In vivo potentiation of 5-fluorouracil by leucovorin in murine colon carcinoma. Biomed Pharmacother 42: 387-393, 1988.

12. Wright JE, Dreyfuss A, El-Magharbel I, Trites D, Jones SM, Holden SA, Rosowsky A and Frei E: Selective expansion of 5,10 -methylenetetrahydrofolate pools and modulation of 5 -fluorouracil antitumor activity by leucovorin in vivo. Cancer Res 49: 2592-2596, 1989.

13. Keyomarsi K and Moran RG: Folinic acid augmentation of the effects of fluoropyrimidines on murine and human leukemic cells. Cancer Res 46: 5229-5235, 1986.

14. Keyomarsi K and Moran RG: Mechanism of the cytotoxic synergism of fluoropyrimidines and folinic acid in mouse leukemic cells. J Biol Chem 263: 14402-14409, 1988.

15. Doroshow JH, Multhauf P, Leong L, et al: Prospective randomized comparison of fluorouracil versus fluorouracil and high-dose continuous infusion leucovorin calcium for the treatment of advanced measurable colorectal cancer in patients previously unexposed to chemotherapy. J Clin Oncol 8: 491-501, 1990.

16. Erlichman C, Fine S, Wong A and Elhakim T: A randomized trial of fluorouracil and folinic acid in patients with metastatic colorectal carcinoma. J Clin Oncol 6: 469-475, 1988.

17. Petrelli N, Douglass HO, Herrera L, et al: The modulation of fluorouracil with leucovorin in metastatic colorectal carcinoma: a prospective randomized phase III trial. Gastrointestinal Tumor Study Group. J Clin Oncol 7: 1419-1426, 1989. 
18. Poon MA, O'Connell MJ, Moertel CG, et al: Biochemical modulation of fluorouracil: evidence of significant improvement of survival and quality of life in patients with advanced colorectal carcinoma. J Clin Oncol 7: 1407-1418, 1989.

19. Priest DG, Schmitz JC, Bunni MA and Stuart RK: Pharmacokinetics of leucovorin metabolites in human plasma as a function of dose administered orally and intravenously. J Natl Cancer Inst 83: 1806-1812, 1991.

20. Schmitz JC, Grindey GB, Schultz RM and Priest DG: Impact of dietary folic acid on reduced folates in mouse plasma and tissues. Relationship to dideazatetrahydrofolate sensitivity. Biochem Pharmacol 48: 319-325, 1994.

21. Spears CP and Gustavsson BG: Methods for thymidylate synthase pharmacodynamics: serial biopsy, free and total TS, FdUMP and dUMP, and $\mathrm{H}_{4}$ PteGlu and $\mathrm{CH}_{2}-\mathrm{H}_{4}$ PteGlu assays. Adv Exp Med Biol 244: 97-106, 1988.

22. Spears CP, Gustavsson BG, Berne M, Frosing R, Bernstein L and Hayes AA: Mechanisms of innate resistance to thymidylate synthase inhibition after 5-fluorouracil. Cancer Res 48 : 5894-5900, 1988.

23. Au JL and Sadée W: The pharmacology of ftorafur (R, S-1(tetrahydro-2-furanyl)-5-fluorouracil. Recent Results Cancer Res 76: 100-114, 1981.
24. Houghton JA, Maroda SJ, Phillips JO and Houghton PJ: Biochemical determinants of responsiveness to 5-fluorouracil and its derivatives in xenografts of human colorectal adenocarcinomas in mice. Cancer Res 41: 144-149, 1981.

25. Lockshin A and Danenberg PV: Biochemical factors affecting the tightness of 5-fluorodeoxyuridylate binding to human thymidylate synthetase. Biochem Pharmacol 30: 247-257, 1981.

26. Danenberg PV and Danenberg KD: Effect of 5, 10-methylenetetrahydrofolate on the dissociation of 5-fluoro-2'-deoxyuridylate from thymidylate synthetase: evidence for an ordered mechanism. Biochemistry 17: 4018-4024, 1978.

27. Van der Wilt CL, Pinedo HM, Smid K and Peters GJ: Elevation of thymidylate synthase following 5-fluorouracil treatment is prevented by the addition of leucovorin in murine colon tumors. Cancer Res 52: 4922-4928, 1992.

28. Peters GJ, Backus HHJ, Freemantle S, van Triest B, CodacciPisanelli G, van der Wilt CL, Smid K, Lunec J, Calvert AH, Marsh S, McLeod HL, Bloemena E, Meijer S, Jansen G, van Groeningen CJ and Pinedo HM: Induction of thymidylate synthase as a 5-fluorouracil resistance mechanism. Biochim Biophys Acta 1587: 194-205, 2002. 